\title{
PENGARUH MODEL PEMBELAJARAN BERBASIS MASALAH TIPE MEANS ENDS ANALYSIS (MEA) TERHADAP KEMAMPUAN BERPIKIR KRITIS MATEMATIS
}

\section{THE INFLUENCE OF MEANS ENDS ANALYSIS (MEA) PROBLEM-BASED LEARNING MODEL ON MATHEMATIC CRITICAL THINKING ABILITY}

\author{
Hevitria $^{1 *}$, Yuanita ${ }^{2}$, Ayen Arsisari ${ }^{3}$ \\ 1,2,3 Pendidikan Guru Sekolah Dasar, Universitas Muhammadiyah Bangka Belitung, Indonesia \\ ${ }^{1}$ bevitria@unmubbabel.ac.id \\ 2yuanita@unmubbabel.ac.id \\ 3ayenarsisari@unmubbabel.ac.id
}

\section{DOI: $10.35438 /$ cendekiawan.v3i2.228}

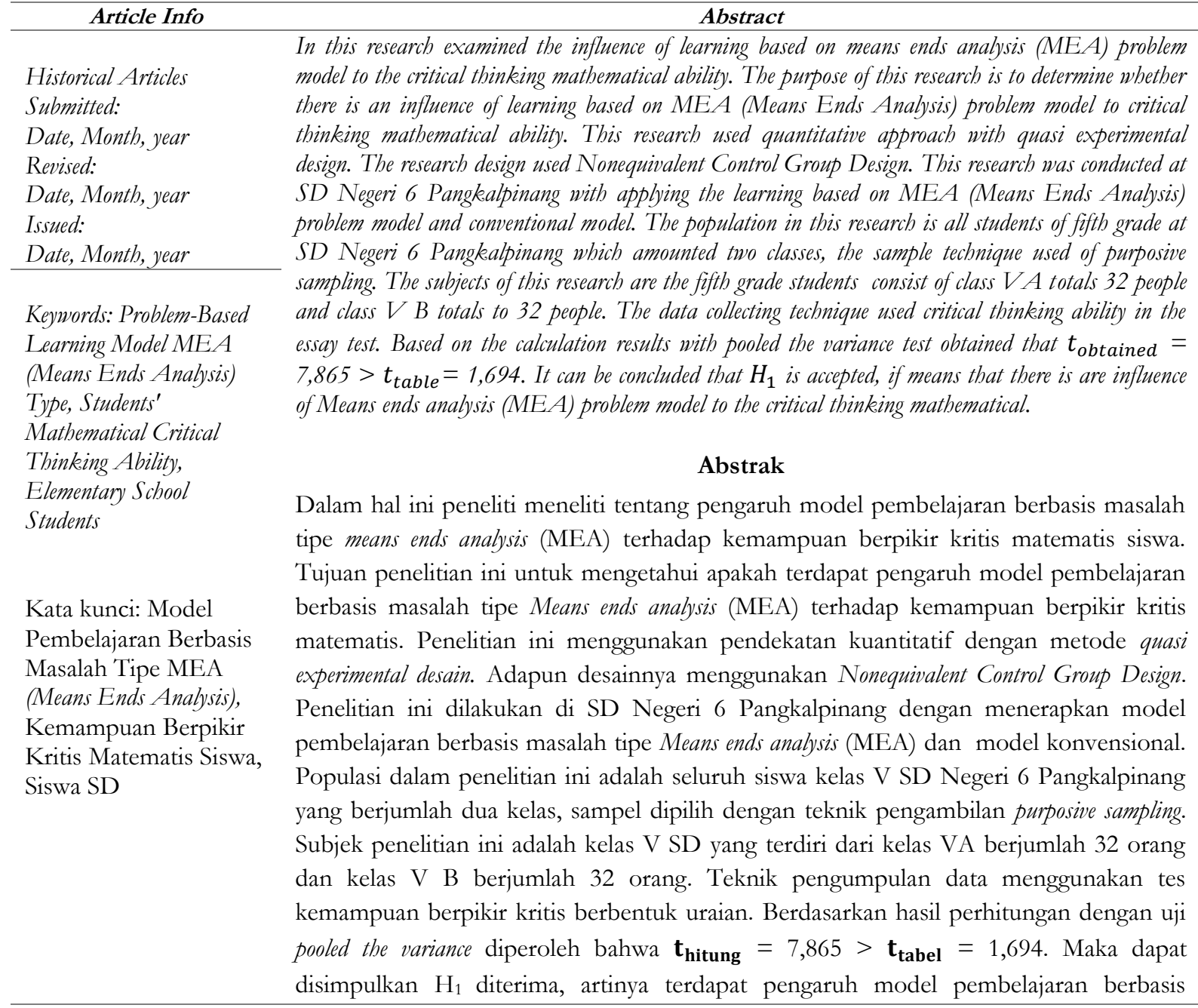


masalah tipe Means ends analysis (MEA) terhadap kemampuan berpikir kritis matematis di kelas V SD Negeri 6 Pangkalpinang.

\section{PENDAHULUAN}

Pembelajaran Matematika adalah proses pemberian pengalaman belajar kepada peserta didik melalui serangkaian kegiatan yang terencana sehingga peserta didik memperoleh kompetensi tentang bahan matematika yang dipelajari (Hartati, 2019). Tujuan pembelajaran Matematika di sekolah dasar agar siswa mampu dan terampil menggunakan matematika. Selain itu juga, dengan pembelajaran matematika dapat memberikan tekanan penataran nalar dalam penerapan matematika (Shofa \& Surjono, 2018).

Berpikir kritis dalam matematika yang didefinisikan adalah pemikiran yang masuk akal untuk memutuskan apa yang harus dipercaya dan dilakukan (Danni \& Tauratiya, 2020). Dalam hal ini, siswa dituntut untuk dapat memahami konsep dan menyelesaikan permasalahan matematika dengan menggunakan langkah-langkah yang sistematis dan masuk akal.

Berdasarkan hasil wawancara ditemukan beberapa permasalahan diantaranya: 1) masih rendahnya kemampuan berpikir kritis siswa, hal ini ditandai dengan rendahnya pemahaman siswa mengenai konsep matematika; 2) proses mengajar dengan penggunaan model konvensional sehingga pembelajaran berpusat pada guru; 3) kurang memotivasi siswa dalam membangun pengetahuannya dan kurang memanfaatkan potensi siswa yang telah ada agar menjadi aktif dan mandiri dalam pembelajaran berlangsung; 4) siswa kurang mampu membangun pengetahuannya sendiri dan lebih suka mendengar ceramah dari guru; 5) siswa kurang menyampaikan pendapat dalam diskusi kelompok

Permasalahan dalam pembelajaran di atas berdampak pada kemampuan berpikir kritis siswa. Berdasarkan hasil ulangan harian, masih banyak siswa yang mendapat nilai kurang dari kriteria ketuntasan minimal (KKM). KKM pada mata pelajaran Matematika adalah 65 dan masih banyak terdapat siswa yang di bawah 65. Dari 33 jumlah siswa di kelas V SD Negeri 6 Pangkalpinang, terdapat 15 siswa yang mendapat nilai di bawah 65 . Nilai terendah yaitu 18 dan nilai tertinggi yaitu 93.

Sebagai usaha untuk memecahkan permasalahan tentang kemampuan berfikir kritis siswa perlu diterapkan model pembelajaran yang tepat, sehingga dapat meningkatkan kemampuan berpikir kritis dalam pembelajaran matematika. Pendidik terus berusaha menyusun serta menerapkan berbagai model dan variasi agar siswa tertarik dan bersemangat dalam belajar matematika (Ilmasari \& Alhadi, 2019). Salah satunya dengan menerapkan model Pembelajaran Berbasis Masalah tipe MEA (Means Ends Analysis).

Pembelajaran berbasis masalah suatu model pembelajaran yang menghadapkan peserta didik pada tantangan "belajar untuk belajar" (Hartati, 2019). Siswa aktif bekerja sama di dalam kelompok untuk mencari solusi permasalahan dunia nyata. Permasalahan ini sebagai acuan bagi peserta didik untuk merumuskan, menganalisis, dan memecahkannya (Shinta Nur Baeti, 2014).

Berdasarkan hasil observasi awal dapat disimpulkan bahwa terdapat pengaruh model pembelajaran berbasis masalah tipe means ends analysis terhadap kemampuan berpikir kritis matematis siswa. Hal ini telah dibuktikan dari hasil penelitian oleh (Noviyanti et al., 2019) terdapat adanya perbedaan peningkatan kemampuan penalaran matematis antara siswa kelas Pembeajarvan MeansEnds Analysis dengan siswa kelas Pembelajaran Ekspositori.

Kemudian berdasarkan penelitian (Hernaeny et al., 2019), bahwa terdapat faktor lain yang mempengaruhi perbedaan kemampuan pemecahan masalah matematis siswa yang memperoleh model Means-Ends Analysis dengan siswa yang memperoleh model konvensional. 
Berdasarkan masalah tersebut maka perlu dilakukan penelitian tentang pengaruh model pembelajaran berbasis masalah tipe means ends analysis terhadap kemampuan berpikir kritis matematis siswa di Kelas V SD Negeri 6 Pangkalpinang.

\section{METODE}

Penelitian ini menggunakan pendekatan kuantitatif dengan metode quasi eksperimen dan jenis rancangan Pretest-Postest pada kelompok takekuivalen yang termasuk Independent (Ananda \& Rafida, 2017). Dalam penelitian eksperimen ini melibatkan dua kelompok, satu kelas sebagai kelompok eksperimen dan satu kelas sebagai kelompok kontrol. Kelompok eksperimen menerima perlakuan dengan menerapkan model pembelajaran berbasis masalah tipe means ends analysis, sedangkan kelompok kontrol menerima perlakuan dengan menerapkan metode konvensional yaitu berpusat pada guru. Kelompok ekperimen maupun kelompok kontrol tidak dipilih secara random namun dipilih secara langsung tanpa diacak. Kelompok kontrol diperlukan untuk melihat perbandingan perlakukan yang baru lebih efektif dari pada perlakuan yang biasa.

Tempat pelaksanaan penelitian ini adalah di SD Negeri 6 Pangkalpinang. Penelitian ini dilaksanakan 8 kali pertemuan pada kelas eksperimen dan kelas kontrol. Pada kelas eksperimen, pertemuan pertama memberikan pretest, pertemuan kedua dan ketiga menerapkan model pembelajaran berbasis masalah tipe means ends analysis dan pertemuan keempat memberikan posttest. Pada kelas kontrol, pertemuan pertama pretest, pertemuan kedua dan ketiga menerapkan pendekatan konvensional, dan pertemuan keempat memberikan posttest.

Populasi merupakan seluruh unsur subjek yang berhubungan dengan penelitian (Muriyanto, 2019). Dengan demikian populasi dalam penelitian ini adalah seluruh siswa kelas V SD Negeri 6 Pangkalpinang. Pengambilan sampel dalam penelitian ini menggunakan teknik Sampling Jenuh. Dalam penelitian ini menggunakan desain yang tidak dipilih secara acak antara kelompok kontrol dan kelompok eksperimen. Sampel dalam penelitian ini adalah kelas VA yang terdiri dari 32 siswa dan kelas VB yang terdiri dari 32 siswa. Dari kedua kelas yang terpilih tersebut, kelas VB digunakan sebagai kelas eksperimen dan kelas VA digunakan sebagai kelas kontrol. Kelas eksperimen memperoleh perlakukan pembelajaran model pembelajaran berbasis masalah tipe Means-Ends Analysis (MEA), sedangkan kelas kontrol memperoleh perlakukan pembelajaran biasa.

Teknik pengumpulan data dalam penelitian ini dilakukan dengan cara tes dan non tes. Pengumpulan data berupa tes tertulis dari soal-soal uraian mengenai KPK dan FPB (Kpk \& Material, 2020). Banyak soal yang diberikan adalah 5 soal. Adapun soal tes yang diberikan berkaitan dengan indikator kemampuan berpikir kritis yaitu pertama; memberikan penjelasan sederhana (Elementary Clarific Ation), kedua; membangun keterampilan dasar (Basic Suport), ketiga; menyimpulkan (Inference), keempat; membuat Penjelasan lebih lanjut (Advanced Clarification).

Teknik analisis data menggunakan pengujian normalitas data dengan menggunakan teknik liliefors. Sedangkan uji homogenitas data menggunakan uji Fisher. Uji hipotesis untuk mengetahui pengaruh kemampuan berpikir kreatif menggunakan uji t tipe The pooled variance model t-test (Dian Apriyant, Hamdah Siti Hamsanah Fitriani, 2020).

\section{HASIL PENELITIAN}

Dalam penelitian ini, langkah-langkah analisisnya yaitu analisis indikator berpikir kritis, uji prasyarat analisis dan uji hipotesis. Uji prasyarat analisis dalam penelitian ini adalah uji normalitas untuk mengetahui apakah data yang diperoleh berdistribusi normal atau tidak dan uji homogenitas untuk mengetahui apakah data berasal dari populasi yang homogen atau tidak homogeny (Harmita, 2004). Uji hipotestis dalam penelitian ini adalah uji $\mathrm{T}$ tipe The pooled variance model t-test untuk 
mengetahui pengaruh model pembelajaran berbasis masalah tipe means ends analysis terhadap kemampuan berpikir kritis matrmatis.

Kemampuan berpikir kritis siswa diperoleh dari pemberian pada soal tes yaitu sebelum dan sesudah perlakuan. Soal pretest di kelas eksperimen dan kontrol diberikan sebanyak 5 butir soal dengan penilaian berpikir kritis sebanyak 4 indikator yang digunakan untuk menilai soal, setiap soal yang diberikan dengan pedoman penelitian melihat dari rubrik penskoran. Indikator pertama yaitu memberikan penjelasan sederhana (elementary clarification), Pada indikator ini $77,2 \%$ siswa kelas eksperimen dan 70,4\% siswa kelas kontrol sudah dapat memberikan penjelasan sederhana dari soal. Indikator kedua yaitu membangun keterampilan dasar (basic support), pada indikator ini 68,35\% siswa kelas kespeirmen dan 63,17\% siswa kelas kontrol sudah dapat membangun keterampilan dasar mereka. ndikator yang ketiga yaitu membuat simpulan (inferring), pada indikator ini siswa hanya mencapai 57,8\% siswa kelas eksperimen dan 51,96\% siswa kelas kontrol dalam membuat simpulan. Indikator yang keempat yaitu membuat penjelasan lebih lanjut (advanced clarification), pada indikator ini pencapaian siswa kelas eksperimen 60,6\% dan siswa kontrol hanya 56,4\%.

Soal posttest di kelas ekspeirmen dan kontrol diberikan sebanyak 5 butir soal dengan penilaian indikator berpikir kritis sebanyak 4 indikator. Pada indikator 1 yaitu memberikan penjelasan sederhana (Elementary Clarification), pada indikator ini kelas ekperimen 88,4\% memberikan penjelasan sederhana dan 83,6\% di kelas kontrol. Pada indikator 2 membangun keterampilan dasar Basic Support), pada indikator ini 85,16\% kelas eksperimen membangun keterampilan dasar dan 79,4\% kelas kontrol. Indikator 3 yaitu membuat simpulan (Inference), pada indikator ini 82,3\% kelas eksperimen membuat simpulan dan 69\% kelas kontrol. Indikator 4 yaitu memberikan penjelasan lebih lanjut (Advance Clarification), pada indikator ini 82,8\% kelas eksperimen memberikan penjelasan lebih lanjut dan 77,6\% kelas kontrol.

Adapun hasil hitungan normalitas dapat dilihat pada tabel 1.

Tabel 1. Hasil uji normalitas pretest kelas eksperimen dan kontrol

\begin{tabular}{ccccc}
\hline \multirow{2}{*}{ Hasil } & \multirow{2}{*}{ Kelas } & \multicolumn{2}{c}{ Liliefors } & \multirow{2}{*}{$\mathrm{H}_{1}$} \\
\cline { 3 - 4 } & & Lhitung & Ltabel & \\
\hline \multirow{2}{*}{ Pretest } & Eksperimen & 0,1489 & 0,157 & \multirow{2}{*}{ Diterima } \\
\cline { 2 - 4 } & Kontrol & 0,1498 & 0,157 & \\
\hline
\end{tabular}

Berdasarkan hasil uji normalitas, didapatkan nilai normalitas pretest kelas eksperimen dengan adalah $L_{h}<L_{t}$ atau 0,1489 $<0,157 \mathrm{maka}_{1}$ diterima, ini artinya data berdistribusi normal. Adapun nilai pretest kelas kontrol adalah $L_{h}<L_{t}$ atau 0,1498 $<0,157$ maka $\mathrm{H}_{1}$ diterima, ini artinya data berdistribusi normal.

Tabel 2. Hasil uji homogenitas pretest kelas eksperimen dan kontrol

\begin{tabular}{clc}
\hline Nilai Varian Sampel & \multicolumn{2}{c}{ Perbandingan hasil Data Pretest Kelas Eksperimen dan } \\
Kontrol
\end{tabular}


Hasil homogenitas nilai pretest kelas eksperimen dan kontrol adalah $\mathrm{F}_{\text {hitung }}=1$,37. Karena $\mathrm{F}_{\text {hitung }}=1,37$ lebih kecil dari $\mathrm{F}_{\text {tabel }}=4,17$ maka $\mathrm{H}_{1}$ diterima, ini artinya data memiliki varians yang sama.

Tabe1 3. Hasil uji perbedaan rata-rata pretest berpikir kritis kelas eksperimen dan control

\begin{tabular}{llll}
\hline Hasil & $\mathrm{T}_{\text {hitung }}$ & $\mathrm{T}_{\text {tabel }}$ & $\mathrm{Df}$ \\
\hline Pretest & 1,102 & 1,694 & 62 \\
\hline
\end{tabular}

Hasil uji perbedaan rata-rata diperoleh bahwa nilai $\mathrm{T}_{\text {hitung }}<\mathrm{T}_{\text {tabel }}$ yaitu 1,102 $>1,694$ maka terima $\mathrm{H}_{0}$, ini artinya tidak terdapat pengaruh model signifikan antara rata-rata pretest berpikir kritis kelas eksperimen dengan kontrol.

Tabel 4. Hasil uji normalitas posttest kelas eksperimen dan kontrol

\begin{tabular}{|c|c|c|c|}
\hline Hasil & Kelas & Liliefors & $\mathrm{H}_{1}$ \\
\hline \multirow{2}{*}{ Posttest } & Eksperimen & 0,134 & \multirow{2}{*}{ Diterima } \\
\hline & Kontrol & 0,1498 & \\
\hline
\end{tabular}

Berdasarkan hasil uji normalitas, didapatkan nilai normalitas posttest kelas eksperimen dengan adalah $L_{h}<L_{t}$ atau 0,134 $<0,157 \mathrm{maka}_{1}$ diterima, ini artinya data berdistribusi normal. Adapun nilai pretest kelas kontrol adalah $L_{h}<L_{t}$ atau 0,1498 $<0,157$ maka $\mathrm{H}_{1}$ diterima, ini artinya data berdistribusi normal.

Tabel 5. Hasil uji homogenitas posttest kelas eksperimen dan control

\begin{tabular}{ccc}
\hline Nilai Varian Sampel & $\begin{array}{c}\text { Perbandingan hasil Data Pretest Kelas } \\
\text { Eksperimen dan Kontrol }\end{array}$ \\
\hline & Kelas Eksperimen & Kelas Kontrol \\
\hline $\mathrm{V}$ & 184,25 & 152,82 \\
\hline $\mathrm{N}$ & 32 & 32 \\
\hline $\mathrm{F}_{\text {hitung }}$ & 1,21 \\
\hline $\mathrm{F}_{\text {tabel }}$ & 4,17 \\
\hline Perbandingan & $1,21<4,17$ \\
\hline
\end{tabular}

Hasil homogenitas nilai posttest kelas eksperimen dan kontrol adalah $\mathrm{F}_{\text {hitung }}=1$,21. Karena $\mathrm{F}_{\text {hitung }}=1,21$ lebih kecil dari $\mathrm{F}_{\text {tabel }}=4,17$ maka $\mathrm{H}_{1}$ diterima, ini artinya data memiliki varians yang sama.

Tabel 6. Hasil uji perbedaan rata-rata posttest berpikir kritis kelas eksperimen dan control

\begin{tabular}{llll}
\hline Hasil & $\mathrm{T}_{\text {hitung }}$ & $\mathrm{T}_{\text {tabel }}$ & $\mathrm{Df}$ \\
\hline Pretest & 4,682 & 1,694 & 62 \\
\hline
\end{tabular}


Hasil uji perbedaan rata-rata diperoleh bahwa nilai $\mathrm{T}_{\text {hitung }}>\mathrm{T}_{\text {tabel }}$ yaitu 4,682 $>1,694$ maka terima $\mathrm{H}_{1}$, ini artinya ada pengaruh model pembelajaran berbasis masalah tipe means ends analysus terhadap kemampuan berpikir kritis matematis siswa di kelas V SD Negeri 6 Pangkalpinang. Maka penelitian dapat dilanjutkan yaitu pengujian hipotesis. Sebelum menentukan uji hipotesis, terlebih dahulu mencari nilai yang akan digunakan dalam melakukan pengujian hipotesis kemampuan berpikir kritis yaitu nilai pretest- nilai posttest .

Tabel 7. Hasil uji normalitas kemampuan berpikir kritis kelas eksperimen dan kelas kontrol

\begin{tabular}{lllcl}
\hline Kelompok & Tes & $\mathrm{L}_{\text {hitung }}$ & $\mathrm{L}_{\text {tabel }}$ & Ket \\
\cline { 1 - 4 } Eksperimen & Pretest-posttest & 0,1549 & 0,157 & \multirow{2}{*}{ Normal } \\
\cline { 1 - 4 } Kontrol & Pretest-posttest & 0,1443 & 0,157 & \\
\hline
\end{tabular}

Berdasarkan hasil uji normalitas pada tabel 7, didapatkan nilai normalitas kemampuan berpikir

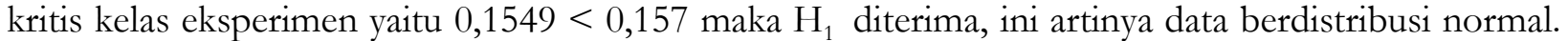
Adapun nilai kelas kontrol adalah $0,1443<0,157$ maka $\mathrm{H}_{1}$ diterima, ini artinya data berdistribusi normal.

Tabel 8. Hasil uji homogenitas kemampuan berpikir kritis kelas eksperimen dan kelas control

\begin{tabular}{llll}
\hline Tes & $\mathrm{F}_{\text {hitung }}$ & $\mathrm{F}_{\text {tabel }}$ & Keterangan \\
\hline Pretest- posttest & 1,19 & 4,17 & Homogen \\
\hline
\end{tabular}

Hasil homogenitas pada tabel 8 kemampuan berpikir kreatif kelas eksperimen dan kontrol adalah $\mathrm{F}_{\text {hitung }}=1,19$.Karena $\mathrm{F}_{\text {hitung }}=1,19$ lebih kecil dari $\mathrm{F}_{\text {tabel }}=4,17$ maka $\mathrm{H}_{1}$ diterima, ini artinya data memiliki varians yang sama.

Tabel 9. Uji-t kemampuan berpikir kreatif kelas eksperimen dan control

\begin{tabular}{lccc}
\hline Kelas & $\mathrm{T}_{\text {hitung }}$ & $\mathrm{T}_{\text {tabel }}$ & $\mathrm{H}_{1}$ \\
\hline Eksperimen dan kontrol & 7,865 & 1,694 & Diterima \\
\hline
\end{tabular}

Berdasarkan hasil hitungan uji t tabel 9 didapatkan $\mathrm{T}_{\text {hitung }}=7,865$ lebih besar dari $\mathrm{T}_{\text {tabel }}=$ 1,694, hal ini menunjukkan bahwa $\mathrm{H}_{1}$ diterima, ini artinya ada pengaruh model pembelajaran berbasis masalah tipe means ends analysis terhadap kemampuan berpikir kritis matematis siswa di kelas V SD Negeri 6 Pangkalpinang.

\section{PEMBAHASAN}

Penelitian ini dilakukan di SD Negeri 6 Pangkalpinang, penelitian ini menggunakan dua kelas untuk membandingkan kelas yang diberi perlakuan yang berbeda seperti yang disampaikan (Ekaputra, 2020) untuk mengetahui perbedaan dari dalam penelitian harus membutuhkan perlakuan yang berbeda. Pada penelitian ini kelas eksperimen yaitu kelas V B yang berjumlah 32 peserta didik, dan kelas kontrolnya kelas V A yang juga berjumlah 32 peserta didik. Pada penelitian ini terdapat dua variabel yaitu variabel bebasnya adalah model pembelajaran berbasis masalah tipe means ends analysis dan variabel terikatnya adalah kemampuan berpikir kritis. Hal itu juga disinggung oleh (Bangun et al., 2020) bahwa variable bebas merupakan variable yang menyesuaikan dengan kondisi tempat penelitian Pada penelitian ini bertujuan untuk mengetahui adanya pengaruh model 
pembelajaran berbasis masalah tipe means ends analysis terhadap kemampuan berpikir kritis matematis siswa di kelas V SD Negeri 6 Pangkalpinang.

Pada saat melaksanakan proses penelitian tahap awal yang dilakukan yaitu melaksanakan pretest (Lestariningsih \& Muafa, 2018) setelah hasil pretest di ketahui dilanjutkan dengan memberikan perlakuan dengan model pembelajaran berbasis masalah tipe means ends analysis siswa di bentuk secara berkelompok untuk memecahkan masalah yang diberikan guru. Hal itu juga disinggung oleh (Sakinah et al., 2018) bahwa penerapan pembelajaran berbasis masalah tipe means ends analysis, memerlukan kelompok kecil dikelas. Untuk kelas kontrol di laksanakan pretest setelah itu mendapatkan perlakuan dengan model konvensional, tahap selanjutnya di laksanakan posttest pada kelas eksperimen dan kelas control (Fuadi, Totok Sumaryanto, 2017), hasil yang diperoleh dikategorikan baik.

Dalam proses pembelajaran di sekolah, siswa tidak sekedar mendengarkan ceramah guru atau berperan serta dalam dalam diskusi, tetapi siswa juga diminta menghabiskan waktunya di perpustakaan, di situs web atau terjun di tengah-tengah masyarakat (Hanum et al., 2020). Penerapan pembelajaran berbasis masalah dalam pembelajaran menuntut kesiapan baik dari pihak guru yang harus berperan sebagai fasilitator sekaligus sebagai pembimbing. Guru dituntut dapat memahami secara utuh dari setiap bagian dan konsep PBM dan menjadi pencegah yang mampu merangsang kemampuan berpikir siswa (Trisnawati, 2013).

Means-Ends Analysis (MEA) terdiri dari tiga unsur kata yakni: means, ends dan analysis. Means berarti banyaknya cara. Sedangkan ends adalah akhir atau tujuan, dan analysis berarti analisa secara sistematis. Jadi, Means-Ends Analysis adalah model pembelajaran yang menganalisis suatu masalah dengan bermacam cara sehingga diperoleh hasil atau tujuan akhir. Hal itu sejalan dengan yang dilakukan oleh (Syifa'ana \& Ramdhani, 2019),

Berdasarkan hasil pengujian Thitung $=7,865>$ Ttabel $=1,694$, ini artinya terima H1 dengan demikian ada pengaruh model pembelajaran berbasis masalah tipe means ends analysis terhadap kemampuan berpikir kritis matematis siswa di kelas V SD Negeri 6 Pangkalpinang.

\section{SIMPULAN}

Berdasarkan hasil penelitian dan pembahasan, dapat disimpulkan bahwa terdapat pengaruh dari model pembelajaran berbasis masalah tipe means ends analysis (MEA) terhadap kemampuan berpikir kritis matematis di kelas V SD Negeri 6 Pangkalpinang. Hal tersebut dapat ditunjukan dengan hasil uji hipotesis dalam penelitian ini yaitu thitung 7,865 > ttabel 1,694 yang menunjukan bahwa H1 diterima yang artinya terdapat pengaruh model pembelajaran berbasis masalah tipe means ends analysis (MEA) terhadap kemampuan berpikir kritis matematis di kelas V SD Negeri 6 Pangkalpinang

\section{REFERENSI}

Ananda, R., \& Rafida, T. (2017). Pengantar evaluasi program pendidikan. In Perdana Publishing (Vol. 53, Issue 9).

Bangun, M., Kelas, D., \& Sdn, I. V. (2020). Pengaruh teori van hiele terhadap prestasi belajar materi bangun datar kelas iv sdn cijoho. Cendekiawan, 2(2), 8-14. https://doi.org/10.35438/cendekiawan.v2i2.183

Danni, R., \& Tauratiya, T. (2020). Analisis Kemampuan Berpikir Kritis Mahasiswa Program Studi Hukum Keluarga Islam IAIN Syaikh Abdurrahman Siddik Bangka Belitung. Tarbawy: Jurnal Pendidikan Islam, 7(1), 17-22. https://doi.org/10.32923/tarbawy.v7i1.1191 
Dian Apriyant, Hamdah Siti Hamsanah Fitriani, C. P. R. (2020). Pengaruh Metode Sosiodrama Terhadap Keterampilan Berbicara Siswa Kelas V Sdn Serpong 1 Kota Tangerang Selatan. Lingua Rima: Jurnal Pendidikan Program Studi Bahasa Dan Sastra Indonesia, 9(1), 1-6.

Ekaputra, F. (2020). Efektivitas Laboratorium Virtual Kimia Berbasis Hypertext Markup Language 5 Untuk Meningkatkan Sikap Ilmiah Dan Prestasi Belajar. Tarbawy: Jurnal Pendidikan Islam, 7(1), 6-16. https://doi.org/10.32923/tarbawy.v7i1.1201

Fuadi, Totok Sumaryanto, W. L. (2017). Pengembangan Instrumen Penilaian Aspek Psikomotor Pembelajaran Ipa Materi Tumbuhan Hijau Kelas V Berbasis Kompetensi Pendekatan Sea Berwawasan Konservasi. Jurnal of Educational and Evaluation, 6(1), 10-18.

Hanum, F., Harahap, N. J., Hsb, E. R., Nirmala, M., Hasibuan, S., Labuhanbatu, U., Tinggi, P., \& Globalisasi, E. (2020). Pembelajaran Mata Kuliah Bahasa Indonesia. Jurnal Education and Development Institut Pendidikean Tapanuli Selatan, 8(3), 33-36.

Harmita. (2004). Petunjuk Pelaksanaan Validasi Metode Dan Cara Perhitungannya. Majalah Ilmu Kefarmasian, 1(3), 117-135.

Hartati, S. (2019). A Efforts to Improve Student Learning Outcomes of Class IV of SD Negeri Seworan Inter-line Relations Material through Realistic Mathematics Education (RME) Approach with Concrete Media. Cendekiawan, 1(2), 28-42. https://doi.org/10.35438/cendekiawan.v1i2.164

Hernaeny, U., Afina, A., \& Nusantari, D. O. (2019). Pengaruh Model Pembelajaran Means Ends Analisis ( MEA ) Terhadap Kemampuan Berpikir Kritis Matematika. Jurnal Kajian Pendidikan Matematika, 5(1), 127-134.

Ilmasari, F., \& Alhadi, S. (2019). Peran Kepala Sekolah Dalam Mengembangkan Kultur Sekolah Di Sd Muhammadiyah Sangonan 2. Jurnal Fundadikdas (Fundamental Pendidikan Dasar), 2(1), 19. https://doi.org/10.12928/fundadikdas.v2i1.677

Kpk, F. P. B., \& Material, K. P. K. (2020). The Influence of Dakota Media and Activeness on Student Achievement in. Cendekiawan, 2(2), 95-103.

Lestariningsih, W., \& Muafa, A. (2018). Pengaruh Model Pembelajaran Self Directed Learning Dan Small Group Discussion Terhadap Nilai Mahasiswa Materi Mekatronik. Teknika: Engineering and Sains Journal, 2(1), 67-72. https://e-journal.umaha.ac.id/index.php/teknika/article/view/216

Muriyanto, M. (2019). The Constraints in Teaching Islamic Education in Class. Cendekiawan, 1(2), 16-27. https://doi.org/10.35438/cendekiawan.v1i2.159

Noviyanti, D., Siswanah, E., \& Fitriani, U. (2019). Efektivitas Strategi Pembelajaran Means Ends Analysis (Mea ) Terhadap. Jurnal Pendidikan Sains Dan Matematika, 9(1), 10-19.

Sakinah, E., Abdul, D., \& Lidinillah, M. (2018). Pedadidaktika: Jurnal Ilmiah Pendidikan Guru Sekolah Dasar Penggunaan Model Means Ends Analysis ( MEA) untuk Meningkatkan Kemampuan Berpikir Kritis Matematis Siswa pada Materi Penjumlahan dan Pengurangan Pecahan. PED ADID AKTIKA: Jurnal Ilmiah Pendidikan Guru Sekolah Dasar, 5(4), 149-156.

Shinta Nur Baeti, A. B. dan E. S. J. (2014). Pembelajaran Berbasis Praktikum Bervisi Sets Dan Penguasaan Kompetensi. Jurnal Inovasi Pendidikan Kimia, 8(1), 1260-1270. 
Shofa, H., \& Surjono, H. D. (2018). Pengembangan multimedia pembelajaran berbasis role playing games (RPG) pada materi lingkaran untuk siswa SMP/MTs kelas VIII. Jurnal Inovasi Teknologi Pendidikan, 5(2), 151-164. https://doi.org/10.21831/jitp.v5i2.15048

Syifa'ana, S. W., \& Ramdhani, S. (2019). Penerapan Model Pembelajaran Reciprocal Teaching untuk Meningkatkan Kemampuan Pemecahan Masalah Matematis Siswa. UNION: Jurnal Ilmiah Pendidikan Matematika, 7(2), 263. https://doi.org/10.30738/union.v7i2.4539

Trisnawati, D. (2013). Implementasi Pembelajaran Berbasis Budaya pada Kelas IV di SD Negeri Godean 2 Sleman Yogyakarta. In Journal of Chemical Information and Modeling (Vol. 53, Issue 9). 